No. 10-3

\title{
A Short Survey of Network Economics
}

\section{Oz Shy}

\begin{abstract}
:
This paper surveys a variety of topics related to network economics. Topics covered include: consumer demand under network effects, compatibility decisions and standardization, technology advances in network industries, two-sided markets, information networks and intellectual property, and social influence.
\end{abstract}

Keywords: survey, network economics, network industries, network effects, network externalities

\section{JEL Classifications: D4, L1, L8, Z1}

Oz Shy is an economist in the research department of the Federal Reserve Bank of Boston. His e-mail address is oz.shy@bos.frb.org.

This paper, which may be revised, is available on the web site of the Federal Reserve Bank of Boston at http://www.bos.frb.org/economic/wp/index.htm.

I thank Jeff Church, Suzanne Lorant, Victor Tremblay, and two anonymous reviewers for most valuable comments and suggestions on earlier drafts.

The views and opinions expressed in this paper are those of the author and do not necessarily represent the views of the Federal Reserve Bank of Boston or the Federal Reserve System.

This version: March 31, 2010 


\section{Introduction}

Network effects are a special type of externality in which consumers' utility and/or firms' profits are directly affected by the number of consumers and/or producers using the same (or a compatible) technology. Loosely speaking, network effects are generated by increasing the adoption rate (popularity) of a good or a service. Consumption network effects may be positive, in the sense that consumers benefit from an increase in the number of consumers using the same or a compatible brand; or negative, in which case consumers are worse off when more consumers use the same or a compatible brand. ${ }^{1}$ Negative network effects often are the result of snobbism or vanity, in that a consumer loses the sense of belonging to an elite group when a product is adopted more widely. In most parts of this survey, the term "network" will refer to a group of users (consumers or firms) who use products and services that are based on similar technologies.

Church and Gandal (2005) have argued that network economics applies to situations where consumption consists of systems of complements. This view holds that consumption benefits depend on combining complements: in the case of direct networks this involves establishing interconnections among subscribers. In the case of indirect network effects, the complements are hardware and software. Church, King, and Krause (2008) argue that the source of the externality is the same whether the network effect is direct or indirect. In fact, the three approaches to compatibility analyzed in Section 3 (the network externalities approach, the components approach, and the software variety approach) often result in very similar equilibrium utility as a function of the number of users of a specific brand. That is, as more people buy a specific hardware brand, more software will be written for that specific brand - this makes the equilibrium depend on the number of users rather than on the number of software applications supporting the specific hardware they buy.

When firms capture market share before they encounter competition, the network effects associated with their installed bases generate switching costs, which are the costs of switching

\footnotetext{
${ }^{1}$ In this literature the term brand refers to a product with distinct technical specifications.
} 
from one brand to another incompatible brand. This is because consumers (or firms) may bear short-run costs of disconnecting from their established network of users before being able to fully gain access to a new network of users. In particular, consumers (firms) bear a cost of switching to less popular incompatible brands (technologies). Although network effects and switching costs are related, this survey does not discuss switching costs and instead focuses more directly on network effects. Farrell and Klemperer (2007) provide a recent comprehensive literature survey of switching costs.

Because of space limitations, only a subset of important works are referenced here. The choice of which to include does not reflect any value judgment but is based on a decision to focus on the theoretical foundations and implications of the main ideas and results. Note that parts of the literature have already been summarized in earlier surveys such as Katz and Shapiro (1994), Economides (1996b), Shy (2001), and Farrell and Klemperer (2007).

This article surveys a number of topics related to network economics. The presentation of each topic starts with a short analytical model that demonstrates the logic behind the main results. The analytical model is followed by discussion of the literature and other results. For the analytical part, lower-case Roman letters, such as $n, x, p$, denote endogenously

determined variables; whereas capital Roman and Greek letters, such as $N$ and $\mu$, denote exogenously given parameters.

\section{Market Demand Under Network Effects}

Consumer preferences are said to exhibit positive (negative) network externalities or network effects if consumers' utility is enhanced (reduced) when more consumers use the same or a compatible brand. Note that production network externalities can be defined similarly. For example, production technologies are said to exhibit network effects if a firm's profit is enhanced when more firms adopt the same or compatible technologies. 


\subsection{Subscription to telecommunication services}

There is no better way to start the analysis of network effects than to describe demand for telecommunication services. Telecommunication is a network in which the utility of each user increases with the total number of other users who are reachable via the same network. No consumer would be willing to pay for phone service if no other consumers could be communicated with via the network. Businesses will use fax machines only if other businesses are able to send or receive fax transmissions. No one would pay for an e-mail service if no one else used e-mail, and so on.

Consumers' sensitivity to the size of telecommunication networks can be explained as follows. The number of connections (or links) among $n$ subscribers is given by $L(n)=$ $n(n-1) / 2$. If, for example, the number of subscribers increases from 10 to 11, the number of possible connections increases by $L(11)-L(10)=55-45=10$. Hence, the addition of the 11th subscriber makes 10 additional connections possible

Building on the above observations, Rohlfs (1974) constructed the demand for telecommunication subscriptions, assuming that potential subscribers are indexed by $x$, where $0 \leq x \leq 1$. Consumers indexed by low values of $x$ value the subscription highly, whereas consumers indexed by $x$ close to 1 place a low valuation on this service. Let $p$ denote the subscription fee, and $q^{e}$ the expected total number of subscribers. Then the (expected) utility of a potential subscriber indexed by $x \in[0,1]$ is given by

$$
U_{x}= \begin{cases}(1-\beta x) \alpha q^{e}-p & \text { if she subscribes } \\ 0 & \text { if she does not subscribe }\end{cases}
$$

where $\alpha>0$ measures the intensity of network effects. Higher values of $\alpha$ indicate that consumers place higher value on the ability to communicate with the $q^{e}$ subscribers. In contrast, $\alpha=0$ implies that there are no network effects. The parameter $\beta>0$ captures the degree of consumer heterogeneity with respect to consumers' benefit from this service.

Let there be $N$ potential subscribers of each type $x, x \in[0,1]$. Then, (1) implies that for a given subscription fee $p$, there is a consumer of type $0 \leq x(p) \leq 1$ who is indifferent 
between subscribing and not subscribing. Assuming perfect foresight, the total number of subscribers is $q^{e}(p)=N x(p)$. Hence, the inverse demand function for this telecommunication service is $p=[1-\beta x(p)] \alpha N x(p)$, which is plotted in Figure 1.
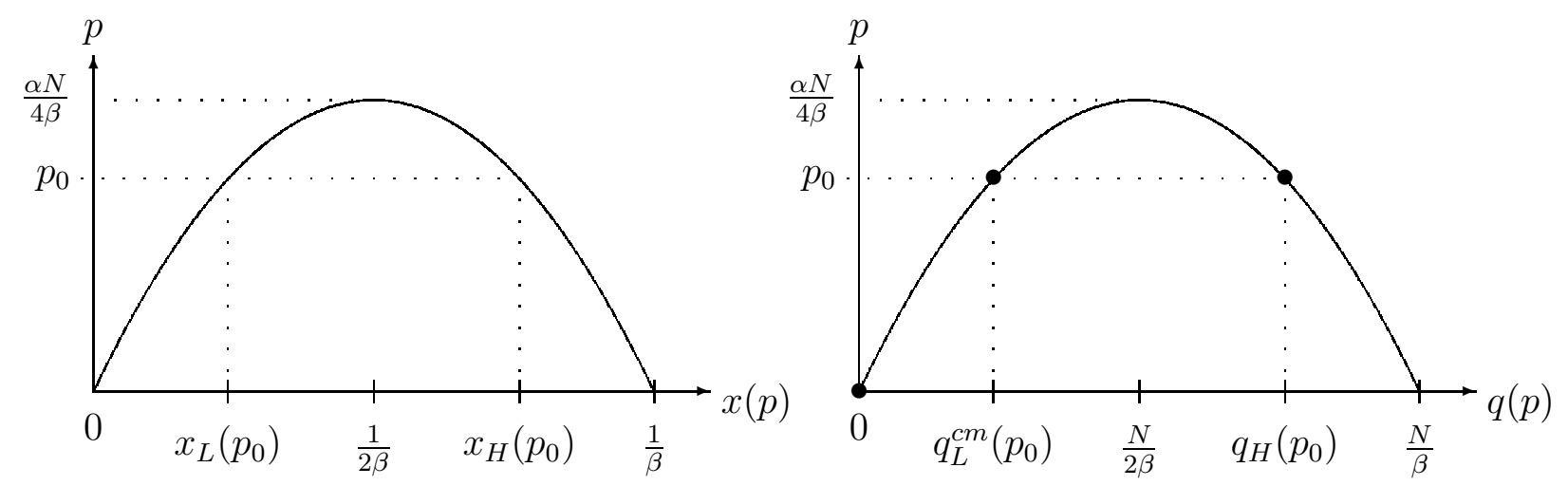

Figure 1: Demand for a telecommunication service under network effects. Left: Subscription fee as a function of $x$ (consumer type). Right: As a function of $q=N x$ (number of subscribers). Bullets denote three equilibria associated with the subscription price $p_{0}$.

Figure 1 shows that the maximum price that can be charged is $p=\alpha N /(4 \beta)$. An increase in the network parameters $\alpha$ and/or population density $N$ stretches the curve upwards, thereby increasing all consumers' willingness to pay. For all prices $0<p_{0}<\alpha N /(4 \beta)$, the demand correspondence takes two values $x_{L}\left(p_{0}\right)=(\alpha N-\sqrt{\cdot}) /(2 \alpha N \beta)$ and $x_{H}\left(p_{0}\right)=(\alpha N+$ $\sqrt{\cdot}) /(2 \alpha N \beta)$, where $\sqrt{\cdot}=\sqrt{\alpha N(\alpha N-4 \beta p)}$. The corresponding numbers of subscribers are therefore $q_{L}^{c m}\left(p_{0}\right)=N x_{L}\left(p_{0}\right)$ and $q_{H}\left(p_{0}\right)=N x_{H}\left(p_{0}\right)$.

The above analysis demonstrates two common characteristics of consumer demand and choice under network effects: (a) Multiplicity of consumer equilibria. At every given price $p_{0}$, if all consumers correctly anticipate low demand, $q_{L}^{c m}$, this level will be realized. In this equilibrium, only those who value this service highly $\left(0 \leq x<x_{L}\left(p_{0}\right)\right)$ will subscribe. If all consumers anticipate high demand, the gain from a larger anticipated network will also induce consumers with lower valuations $\left(x_{L}\left(p_{0}\right)<x \leq x_{H}\left(p_{0}\right)\right)$ to subscribe. The low demand $q_{L}^{c m}\left(p_{0}\right)$ is called the critical mass of subscribers at price $p_{0}$. It is the minimum number of subscribers that the service provider must secure in order to ensure nonzero demand for this service. Note that $q_{L}^{c m}\left(p_{0}\right)$ is an unstable equilibrium in the sense that a 
small increase in the number of subscribers would induce $q_{H}\left(p_{0}\right)$ consumers to subscribe. (b) Coordination problems. Consumers must know the actual number of other subscribers in order to make a decision concerning whether to subscribe. For example, $q(p)=0$ (zero demand) is always an equilibrium if all consumers believe that no one will subscribe, in which case this belief is self-fulfilling.

In the literature, Taylor (1994) provides an extensive analysis of telecommunications demand and also raises the possibility that the subscription externality could turn negative at higher levels of penetration (I return to the issue of negative network effects in Section 7). Economides and Himmelberg (1995a) demonstrate that the critical mass is independent of the market structure. Indeed, Figure 1 illustrates that the notion of critical mass refers to a consumer equilibrium that is independent of industry supply as determined by market structure. Oren and Smith (1981) generalize Rohlfs's model to multiple subscribers and multipart tariffs. ${ }^{2}$ Becker (1991) and Karni and Levin (1994) characterize demand functions with network effects that explain why some entertainment places do not raise prices even when subjected to persistent excess demand and high popularity.

\subsection{Empirical testing of the network externalities hypothesis}

Several authors have empirically tested the network externalities assumption. Gandal (1994) estimates hedonic (quality-adjusted) price equations for spreadsheet programs to test whether network externalities exist and shows that consumers are willing to pay a significant premium for spreadsheets that are compatible with the Lotus platform and for spreadsheets that offer links to external databases. Brynjolfsson and Kemerer (1996) investigate the relationship between the installed base and the price of a software package and show that a 1 percent increase in a product's installed base was associated with a 0.75 percent increase in price. As for compatibility, they show that products that adhered to the then-popular Lotus menu tree interface were priced higher by an average of 46 percent. Gandal (1995) tests for network

\footnotetext{
${ }^{2}$ In addition, Bensaid and Lesne (1996) and Cabral, Salant, and Woroch (1999) investigate whether a monopolist would profit from setting a low introductory price to attract a critical mass of adopters, and how the network effects mitigate the time inconsistency problem faced by a dynamic monopoly.
} 
externalities by looking at file-transfer compatibility standards and finds that only the Lotus file compatibility standard is significant in explaining price variations. Dranove and Gandal (2003) characterize network effects in the DVD market by examining empirically how the preannouncement of the commpeting DIVX standard temporarily slowed the adoption of the DVD technology. Grajek (2010) finds strong network effects in the Polish mobile telephone market during 1996-2001, and shows that ignoring network effects leads to overestimation of demand elasticity.

Economides and Himmelberg (1995b) use a similar demand structure to calibrate for the parameters that measure consumers' valuation of network effects, using aggregate time-series data on prices and quantities in the U.S. fax market. Using sales data from 1979 to 1992 , they show that the surge in demand toward the end of the 1980s was not driven by outside shifts in consumer demand and price reductions as much as by the feedback effect induced by both past increases and anticipated future increases in the size of the installed base.

Gowrisankaran and Stavins (2004) test for and estimate the magnitude of network externalities in the Federal Reserve automated clearinghouse ( $\mathrm{ACH})$ payment system. They identify network externalities from technological advancement, peer group effects, economies

of scale, and market power. Based on their results, which indicate that ACH appears to be underused relative to its socially optimal level due to network externalities, the authors conclude that the Federal Reserve should encourage ACH adoption and use.

\section{Compatibility and Competition}

Competing brands are said to be compatible if they can work together in the sense that they operate on the same standard. Figure 2 displays the three commonly used methods of modeling interbrand compatibility.

In Figure 2a (the network externalities approach), brands $A$ and $B$ are said to be compatible if the utility of a brand $A$ user is enhanced by an increase in the number of brand $B$ 


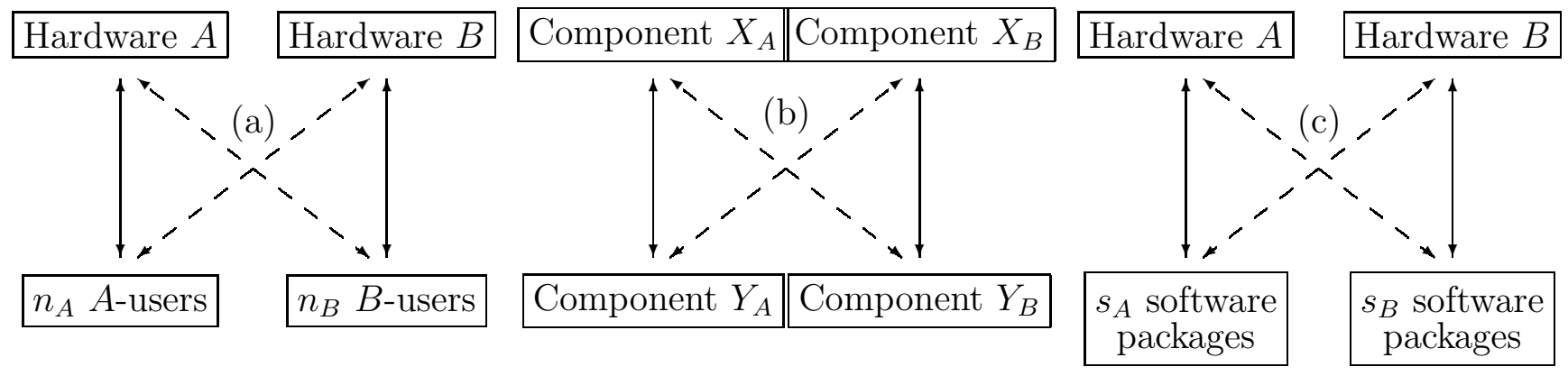

Figure 2: Three approaches to compatibility: (a) The network externalities approach. (b) The components approach. (c) The software variety approach. Note: Dashed arrows indicate direction of compatibility.

users, and the utility of a brand $B$ user is enhanced by an increase in the number of brand $A$ users. In Figure 2b, (the components approach), brands $A$ and $B$ are called compatible if consumers can purchase hybrid systems composed of components made by different manufacturers, such as $X_{A} Y_{B}$ and $X_{B} Y_{A}$ in addition to systems $X_{A} Y_{A}$ and $X_{B} Y_{B}$. In Figure 2c (the software variety approach) brands $A$ and $B$ are compatible if machine $A$ can run software written specifically for machine $B$ and the other way around. Note that so far we have interpreted compatibility as two-way compatibility. However, compatibility need not be symmetric in the sense that it is possible for machine $A$ to be $B$-compatible while machine $B$ is incompatible with machine $A$, a situation that we call one-way compatibility.

Hardware producing firms may compete in prices (Bertrand) or in quantities (Cournot). As is shown below, equilibrium prices are highly sensitive to whether firms produce compatible or incompatible brands. The following three subsections analyze three different approaches to analyzing compatibility.

\subsection{The network externalities approach}

Equilibrium hardware prices in the presence of network effects are often hard to compute. This is because when consumers' preferences exhibit network effects, firms that produce incompatible brands generally benefit from undercutting rivals' prices in order to enlarge the number of their networks' users. Let there be two brand-producing firms, $A$ and $B$, 
priced at $p_{A}$ and $p_{B}$, respectively. $n_{A}$ and $n_{B}$ denote the endogenously determined number of new consumers who buy brands $A$ and $B$. Suppose firms $A$ and $B$ have already sold their products to $N_{A}$ and $N_{B}$ old consumers. $N_{i}$ will be referred to as firm $i$ 's installed base, $i=A, B$. Assuming equal-size cohorts implies that the total number of old consumers equals the total number of new consumers, $N_{A}+N_{B}=n_{A}+n_{B}=N$.

There are $N$ new consumers who are uniformly indexed by $x$ on the unit interval $[0,1]$ according to increasing preference for brand $B$. Define the utility of each new consumer of type $x$ by

$$
U_{x} \stackrel{\text { def }}{=} \begin{cases}\alpha\left(N_{A}+n_{A}\right)-p_{A}-\delta x & \text { buys brand } A ; A \text { and } B \text { are incompatible } \\ \alpha\left(N_{B}+n_{B}\right)-p_{B}-\delta(1-x) & \text { buys brand } B ; A \text { and } B \text { are incompatible } \\ \alpha 2 N-p_{A}-\delta x & \text { buys brand } A ; A \text { is } B \text {-compatible } \\ \alpha 2 N-p_{B}-\delta(1-x) & \text { buys brand } B ; B \text { is } A \text {-compatible. }\end{cases}
$$

The parameter $\alpha$ measures the intensity of network effects. If $\alpha=0$, there are no network effects and the model collapses to the standard Hotelling (1929) location model. This section focuses on the case where there are positive network effects, $\alpha>0$, so the utility of each consumer is enhanced by an increase in the number of consumers using the same or a compatible brand. Section 7 analyzes negative network effects, such as snobbism and vanity, where $\alpha<0$. The parameter $\delta>0$ measures the degree of brand differentiation. The utility function (2) implies that new consumers who are indifferent between buying $A$ and $B$ are indexed by

$$
\hat{x}^{I}=\frac{\delta+\alpha\left(N_{A}-N_{B}-N\right)+p_{B}-p_{A}}{2(\delta-\alpha N)} \quad \text { and } \quad \hat{x}^{c}=\frac{1}{2}+\frac{p_{B}-p_{A}}{2 \delta},
$$

where superscripts " $I$ " and " $C$ " denote incompatible and compatible brands, respectively. Ignoring production costs, in the market for new consumers (old consumers do not buy), firm $A$ chooses a price $p_{A}$ to maximize profit (revenue in the present example), $\pi_{A}=p_{A} n_{A}=$ $p_{A} x N$. Firm $B$ chooses a price $p_{B}$ to maximize profit, $\pi_{B}=p_{B} n_{B}=p_{B}(1-x) N$. To focus on equilibria in which the two incompatible standards prevail, it is assumed that network effects are bounded by $\alpha<\delta /(2 N)$. Hence, the Nash-Bertrand equilibrium prices and profits 
when firms produce incompatible brands are

$$
\begin{aligned}
& p_{A}^{I}=\delta-\frac{2 \alpha\left(N_{a}+2 N_{B}\right)}{3}, \quad p_{B}^{I}=\delta-\frac{2 \alpha\left(2 N_{A}+N_{B}\right)}{3}, \\
& \pi_{A}^{I}=\frac{N\left[3 \delta-2 \alpha\left(N_{A}+2 N_{B}\right)\right]^{2}}{18(\delta-\alpha N)}, \quad \text { and } \quad \pi_{B}^{I}=\frac{N\left[3 \delta-2 \alpha\left(2 N_{A}+N_{B}\right)\right]^{2}}{18(\delta-\alpha N)}
\end{aligned}
$$

However, if the firms produce compatible brands,

$$
p_{A}^{c}=p_{B}^{c}=\delta \quad \text { and } \quad \pi_{A}^{c}=\pi_{B}^{c}=\frac{\delta N}{2} .
$$

For the case of incompatible brands, the above model generates the following results: (a) The firm with the larger installed base $\left(N_{A}>N_{B}\right)$ charges a higher price $\left(p_{A}^{I}>p_{B}^{I}\right)$ and earns a higher profit $\left(\pi_{A}^{I}>\pi_{B}^{I}\right)$. (b) The differences between the brands' equilibrium prices and profit levels increase with consumers' preference for a larger network size (increase in $\alpha$ ). (c) For similar installed bases $\left(N_{A} \approx N_{B}\right)$ firms' equilibrium prices and profits decline with an increase in the network parameter $\alpha$. This shows that price competition is intensified when consumers place a higher value on the size of the network (because this leads firms to reduce prices in order enlarge their network size).

The pioneering paper by Katz and Shapiro (1985) employs an output game (Cournot) rather than a price game (Bertrand) analyzed in the above demonstration. Despite the difference in market structure, Katz and Shapiro also demonstrate firms' profit and social welfare gains from product compatibility. Rather than emphasizing firms' profit motivation for achieving compatibility, Farrell and Saloner (1986b) provide a demand-side welfare evaluation of adoption outcomes, such as "tipping" equilibria (where all users adopt the same standard regardless of their preferences) and multiple standard equilibria (in which consumers adopt different standards according to their preferences). They show that if it is socially optimal to have multiple standards then this outcome can be obtained as an adoption equilibrium. Noam (1992) analyzes a different type of tipping, in which a stable single coalition of telecommunication service providers breaks into a system of separate sub-coalitions. 
The above analysis abstracts from describing the physical networks in which agents interact with each other. In many cases, consumers' utilities are affected not only by the number of consumers using the same or compatible brands but also by whether they are connected. For example, for some services compatibility is important only among the local group of people, but not necessarily important for connecting to groups located far away. Of course, the opposite case may also apply, for example, email connection may be more important for people who are far away from one another.

Books by Goyal (2007), Vega-Redondo (2007), and Jackson (2008) summarize recent literature that models network effects as links (or graphs) among agents or groups of agents. As Jackson and Wolinsky (1996) argue, there are innumerable ways to describe these networks. Figure 3 illustrates one very specific example.

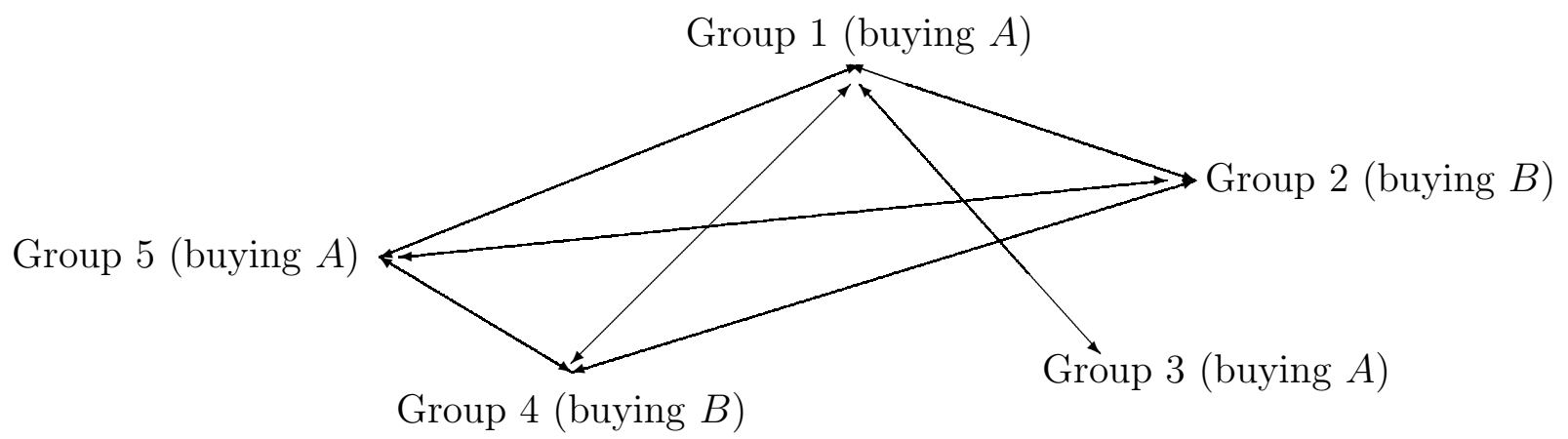

Figure 3: Network effects as links.

In Figure 3, consumer groups 1, 3, and 5 buy brand $A$. Consumer groups 2 and 4 buy brand $B$. Therefore, in the spirit of the utility function (2), consumers' utility levels are: $U_{1}=\alpha\left(N_{1}+N_{3}+N_{5}\right)-p_{A}, U_{2}=U_{4}=\alpha\left(N_{2}+N_{4}\right)-p_{B}, U_{3}=\alpha\left(N_{1}+N_{3}\right)-p_{A}$, and $U_{5}=\alpha\left(N_{1}+N_{5}\right)-p_{A}$. Thus, although both groups 3 and 5 buy brand $A$, they do not share network effects, because they are not linked. Under this configuration, network effects prevail only if the following two conditions are simultaneously satisfied: (i) Agents are linked, and (ii) Agents buy the same brand. ${ }^{3}$

\footnotetext{
${ }^{3}$ Using a similar approach, Banerji and Dutta (2009) demonstrate how network firms can segment and divide up the market and earn positive profits in a Bertrand competition.
} 


\subsection{The components approach}

Matutes and Regibeau (1988) analyze markets for systems composed of two components $X Y$ that are perfect complements. Such markets include computers and displays, stereo receivers and speakers, camera bodies and lenses, and so on. There are two brand-producing firms, $A$ and $B$, each capable of producing both components. A firm can make its components compatible or incompatible with the components produced by the rival firm. If the systems are incompatible, only systems $X_{A} Y_{A}$ and $X_{B} Y_{B}$ are available to consumers, with system prices $p^{A}=p_{X}^{A}+p_{Y}^{A}$ and $p^{B}=p_{X}^{B}+p_{Y}^{B}$. If the firms produce compatible components, consumers can choose from four systems: $X_{A} Y_{A}, X_{B} Y_{B}, X_{A} Y_{B}, X_{B} Y_{A}$ with component prices $p_{A}^{X}, p_{A}^{Y}, p_{B}^{X}, p_{B}^{Y}$.

Consumers are indexed by $x$ and $y$ on the unit square. The utility of a consumer indexed by $(x, y) \in[0,1] \times[0,1]$ is given by

$$
U_{x y}= \begin{cases}\beta-\delta x-\delta y-p_{A}^{X}-p_{A}^{Y} & \text { if buys system } X_{A} Y_{A} \\ \beta-\delta(1-x)-\delta(1-y)-p_{B}^{X}-p_{B}^{Y} & \text { if buys system } X_{B} Y_{B} \\ \beta-\delta(1-x)-\delta y-p_{B}^{X}-p_{A}^{Y} & \text { if buys system } X_{B} Y_{A} \\ \beta-\delta x-\delta(1-y)-p_{A}^{X}-p_{B}^{Y} & \text { if buys system } X_{A} Y_{B}\end{cases}
$$

The last two rows are not relevant if firms produce only incompatible components. The parameter $\delta>0$ measures the degree of brand differentiation. Figure 4 displays the equilibrium allocation of buyers between brand $A$ and $B$ under incompatible and compatible components.
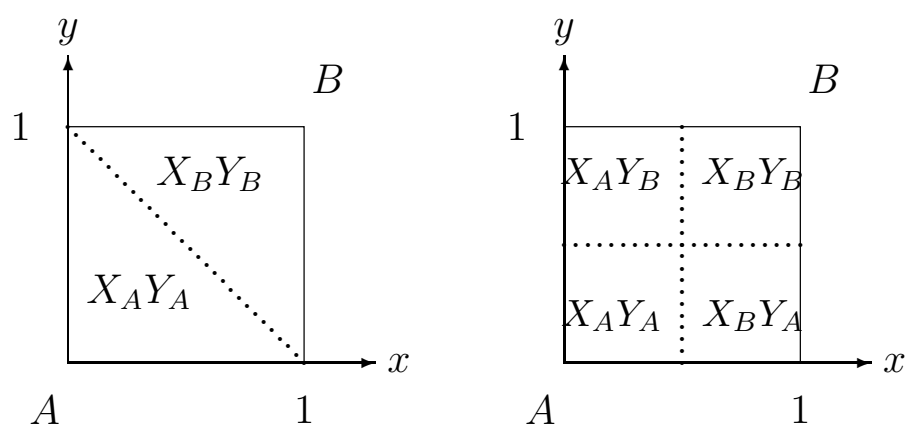

Figure 4: Equilibrium allocation of consumers among systems. Left: Incompatible systems. Right: Compatible systems. 
Figure 4 (right) shows that compatibility enables some consumers to choose systems closer to their "ideal" systems by combining components produced by different manufacturers. However, it turns out that in some cases total consumer welfare is lower when firms produce compatible components than when they produce incompatible components, because firms charge a much higher price when they produce compatible components. In the present example, with zero production costs, the Nash-Bertrand equilibrium prices and profit levels are $p_{A}^{X}=p_{A}^{Y}=p_{B}^{X}=p_{B}^{Y}=\pi^{A}=\pi^{B}=\delta$ under compatibility. Under incompatibility, $p^{A}=p_{X}^{A}+p_{Y}^{A}=\delta, p^{B}=p_{X}^{B}+p_{Y}^{B}=\delta$, and $\pi^{A}=\pi^{B}=\delta / 2$. Therefore, in this example compatibility doubles the price of systems from $\delta$ to $2 \delta$.

The above model predicts that producers' profits are enhanced when they coordinate on a standard that permits the production of compatible components. Consumers on average lose from compatibility; however, total social welfare (the sum of consumers' utility and firms' profits) is higher when firms produce compatible components. Prices are higher under compatibility because demand is less elastic than with incompatibility. Social welfare is higher because there is a closer match between optimal and available system; however, consumer welfare is generally lower because component-producing firms are able extract all the additional compatibility gains from consumers.

Economides (1989) analyzes a similar industry in which consumers have downwardsloping demand for each component or system. Einhorn (1992) demonstrates that the result that producers of components earn higher profits when components are compatible continues to hold in industries with quality (vertical) differentiation. This result holds regardless of whether both components produced by one firm are of higher quality or whether each firm has a quality advantage in only one component. Economides and Salop (1992) generalize Cournot's model of complementary duopoly to the case of multiple brands of compatible components and characterize the conditions on the degree of component substitutability under which the equilibrium system price is lower under joint ownership than with independent ownership of component-producing firms. Finally, Farrell, Monroe, and Saloner (1998) analyze two forms of organizing production: (a) Firms produce and compete in fully assembled 
systems (closed organization). (b) Firms compete in markets for components (open organization). They show that open interaction is always the socially efficient choice because it minimizes costs, but it need not be the most profitable, because low costs are only one of the determinants of profits.

\subsection{The software approach}

The software approach (also known as the supporting services approach or indirect network externalities) replaces the network externalities hypothesis with the assumption that consumers care about the variety of services supporting the specific brand they buy. For example, if computer hardware is incompatible with some software applications, a buyer of a new computer will base her decision on the number of software applications that can operate on a particular brand of hardware. Another example is the market for DVD (digital video disk) players, in which buyers tend to investigate how many movies are available for rental or purchase for the specific DVD format of the player (the two competing formats in this market were Blue-ray and HD DVD).

The relationship between the diffusion of CD players (hardware) and the variety of CD titles (software) has been investigated empirically by Gandal, Kende, and Rob (2000). They estimate the (direct) elasticity of adoption with respect to CD player prices and show that the (cross) elasticity with respect to the variety of CD titles is significant.

A simple way to model hardware competition under the software approach is to replace the utility function (2) by

$$
U_{x} \stackrel{\text { def }}{=} \begin{cases}\alpha s_{A}-p_{A}-\delta x & \text { buys hardware } A ; A \text { and } B \text { are incompatible } \\ \alpha s_{B}-p_{B}-\delta(1-x) & \text { buys hardware } B ; A \text { and } B \text { are incompatible } \\ \alpha\left(s_{A}+s_{B}\right)-p_{A}-\delta x & \text { buys hardware } A ; A \text { is } B \text {-compatible } \\ \alpha\left(s_{A}+s_{B}\right)-p_{B}-\delta(1-x) & \text { buys hardware } B ; B \text { is } A \text {-compatible, }\end{cases}
$$

where $p_{A}$ and $p_{B}$ are hardware prices and $s_{A}$ and $s_{B}$ measure the amount of software written specifically for hardware $A$ and $B$, respectively. Thus, $s_{A}$ and $s_{B}$ could be the actual number 
of computer software applications or movie titles supporting each brand of hardware, or the utility generated from consuming these varieties.

Under the latter interpretation, Chou and Shy (1990) show that the equilibrium utility levels can be expressed as functions of the equilibrium number of buyers $\left(n_{A}\right.$ and $\left.n_{B}\right)$. For this reason, some authors refer to the software approach as indirect network externalities. This terminology is somewhat problematic because there is no real externality here. In fact, most products need some kind of complementary services whose complementarity does not constitute a real externality (see Liebowitz and Margolis (1994)). Church, King, and Krause (2008) use a different classification and establish the conditions required for an externality to exist. Regardless of whether we classify these network effects as an externality or not, it turns out that the analytics of both approaches yield similar results because if, in equilibrium, more people buy hardware $A$ than hardware $B$, then more programmers will find it profitable to write software for $A$ than for $B$. Formally, $s_{A} \geq s_{B}$ if $n_{A} \geq n_{B}$. In this case, the increase in the variety of $A$ software will increase the welfare of $A$ users (see also Church and Gandal $(1993))$.

However, Chou and Shy (1996) demonstrate a class of distribution functions of consumers' tastes for the two brands in which a further increase in the number of consumers who prefer $A$ machines would actually lower the welfare of existing $A$ users. This occurs because the gain from an increase in software variety is dominated by the loss associated with the increase in the price of hardware $A$. Using a similar framework, Church and Gandal (1992) identify a possible market failure in which a high value on software variety would make standardization socially optimal, whereas in equilibrium there might be two incompatible operating standards.

Finally, several authors have observed that when software firms invest in the quality of their product, they do so not only to attract consumers who are already using the compatible hardware, but also to attract consumers who currently use incompatible hardware. Thus, indirect network effects can be driven by the quality, not just by the variety of supporting software. Markovich (2008) studies the conditions under which standardization in the 
hardware market arises and persists over time. Markovich and Moenius (2009) show that a successful software competitor raises the value of all software firms whose products run on the same platform in the sense that an unsuccessful firm may enjoy a windfall increase in its market value.

\subsection{Compatibility decisions}

The previous sections described three approaches to compatibility. This section briefly discusses some results concerning firms' incentives to design their products to be compatible with competing brands. The reader is also referred to Section 4, which analyzes firms' decisions to switch to new technologies.

\subsubsection{Gains from compatibility}

To demonstrate why firms gain from producing compatible brands rather than incompatible brands I focus on the symmetric case in which both firms inherit equal installed bases. Substituting $N_{A}=N_{B}=N / 2$ into the equilibrium prices when the brands are incompatible, given in (3), yields

$$
p_{A}^{I}=p_{B}^{I}=\delta-\alpha N \quad \text { and } \quad \pi_{A}^{I}=\pi_{B}^{I}=\frac{N(\delta-\alpha N)}{2}
$$

Comparing (7) with (4) reveals that prices and profits are higher when both hardware firms produce compatible brands than when they produce incompatible brands. That is, compatibility weakens price competition because firms are less tempted to reduce prices in order to subsidize consumers' switching costs. Formally, compatibility lowers the price elasticity for each firm's brand.

The above result, in which firms of similar size gain from producing compatible brands, is important because it provides an explanation for why firms benefit from agreeing on technological standards, such as those for the compact cassette, compact disc, $8 \mathrm{~mm}$ video cassette, 35mm film, HTML (hyper text markup language), shared ATMs (for banks), and 
so on. Of course, this result does not explain why, in some industries, firms choose to adopt different standards (as in the market for HD videos, which had two competing standards).

\subsubsection{Types of compatibility}

The above demonstration of the gains from compatibility abstracted from some features that may be important for understanding certain markets. First, is compatibility a oneway or a two-way relationship? In other words, if firm $A$ makes its machine compatible with machine $B$ (or $B$ 's software), does it imply that machine $B$ also becomes compatible with machine and/or software $A$ ? Second, can machine compatibility be achieved by one firm, or must both firms agree (or invest) in order to achieve compatibility? Third, do firms with a small market share benefit more from compatibility than firms with a large market share? One might be tempted to argue that small firms always benefit more from compatibility because it allows them to access more consumers, but this intuition may be

incorrect. For example, under the software approach, if the small firm designs its machine to be compatible with software written for the more popular machine, software writers may decrease the amount of software designed specifically the small machine (see Section 3.5 below).

\subsubsection{Compatibility decisions, entry, and antitrust}

Network economics is often in the news when antitrust authorities fear that a firm with a significant market share may be able to preempt competition and maintain its dominance simply because consumers would not find it beneficial to switch to competing firms that sell incompatible brands, and sell to a small number of consumers. U.S. and European court cases concerning Microsoft's Windows operating system provide good examples. Generally there is no law against maintaining a large market share even in network industries. Thus, dominant firms can be challenged only if they "abuse their dominant position" (European competition law) or "monopolize or attempt to monopolize" (Section 2 of the 1890 Sherman Act in U.S. law). 
The above observations raise three questions. First, can dominant firms in network industries maintain their market power by taking small measures that would prevent their customers from switching to incompatible brands? Second, can these measures be used to deter entry of new firms operating on new standards? Third, which action is more profitable for the dominant firm: (i) restricting access to its standard, or (ii) allowing access by making its standard available to competing firms?

Church and Gandal (2005, Sec. 5) discuss two options available to incumbent firms: (i) denying compatibility to competitors by exercising property rights, and (ii) restricting compatibility of new, complementary products. They argue, "It is unlikely that the sponsor(s) of a network with a large installed base will grant compatibility. Doing so enhances intranetwork competition - and in the absence of strong network competition - provides very little benefit to the system sponsor. Compatibility eliminates the installed base advantage of the incumbent, reducing its market power and profits."

However, there are cases in which network externalities may actually support competition. Economides (1996a) shows that if the network effect is sufficiently strong, a Cournot quantity leader has an incentive to invite entry and license its technology without charge. SONY did not use this strategy and as a result it had to abandon its Betamax video technology in 1988 because it refused to license it to competitors, thereby paving the way to VHS standards. Ohashi (2003) estimates the importance of indirect network effects in the U.S. VCR market between 1978 and 1986. He finds that if SONY had aggressively introduced its VCR at an early stage of competition, Beta would likely have dominated the market in 1985.

Finally, Economides and White (1994) argue that vertical relationships are inherent in networks, and that compatibility is a more general concept than complementarity. This enables them to draw on economic and legal concepts to analyze antitrust issues (such as mergers, joint ventures, and vertical restrictions) that are relevant to network industries. 


\subsubsection{Additional literature on compatibility decisions}

The remainder of this section reviews the literature on compatibility choices. ${ }^{4}$

Katz and Shapiro (1986a) analyze private and social incentives to produce compatible products when firms compete in patented technologies. Farrell and Saloner (1988) demonstrate that when standardization is profitable for all parties but the parties cannot agree on which standard to adopt, as in the Battle of the Sexes game, standardization is more likely to be accomplished via formal committees than under sequential independent decisionmaking. However, committees tend to be slower to finalize a decision.

On the issue of market size, Cremer, Rey, and Tirole (2000) analyze providers of Internet backbone services and show that when there are only two providers, the larger backbone provider, which relies less on access to the other's customers, gains a competitive advantage when connectivity is degraded (lower compatibility). However, this need not be the case when there are more than two providers of backbone services. Baake and Boom (2001) analyze compatibility decisions of oligopolistic firms where network externalities interact with other quality dimensions that the firms can control. They show that firms' choice of different quality levels not only weakens price competition but also facilitates the coordination required for achieving compatibility. Chen, Doraszelski, and Harrington (2009) endogenize product compatibility decisions in a dynamic stochastic setting to address the long-run market structure of a product market characterized by network effects. They find that compatibility can indeed be stable in the long run. On the empirical side, Greenstein (1993) finds that the (in)compatibility between a buyer's installed base and a potential system influenced Federal agencies' choice of vendor in purchasing commercial mainframe computers. For example, users with an installed base of IBM equipment were more likely to switch to other vendors if they possessed very old IBM equipment for which compatible upgrades were limited.

\footnotetext{
${ }^{4}$ The results reported in this literature may be sensitive to the assumptions on how compatibility can be achieved.
} 


\subsection{Converters and partial compatibility}

A converter is a piece of hardware or software that makes two brands compatible with each

other. Very often, converters cannot achieve 100-percent compatibility, in which case we say that the two systems are only partially compatible. Farrell and Saloner (1992) analyze partial compatibility of hardware under network externalities and study how the introduction of converters affects welfare. Chou and Shy (1993a) analyze partial compatibility of software (or any other brand-supporting services). de Palma, Leruth, and Regibeau (1999) analyze how allowing consumers to make "double purchases" (buy both brands) affects the degree of compatibility between brands. Choi (1996a) identifies cases in which the use of converters can block the transition to a new, incompatible technology. This can occur because converters enhance the value of the old technology.

To understand the economics of software that is partially compatible, let $s_{A}$ and $s_{B}$ denote the number of software applications written specifically for machines $A$ and $B$, respectively. Assuming that the software industry has a limited number of programmers, full employment implies that $s_{A}+s_{B}=\bar{s}$. Let $\rho_{A}\left(0 \leq \rho_{A} \leq 1\right)$ denote the fraction of $B$-software that can run on an $A$ machine. Define $\rho_{B}$ similarly. Then, the effective number of software applications available to $A$-users and $B$-users, respectively, is $S_{A}=s_{A}+\rho_{A} s_{B}$ and $S_{B}=s_{B}+\rho_{B} s_{A}$.

Consumers will choose the hardware that is supported by the largest effective number of software applications. Therefore, an equilibrium in which both hardware brands coexist must satisfy $S_{A}=S_{B}$, which implies that

$$
s_{A}=\frac{\bar{s}\left(1-\rho_{A}\right)}{2-\rho_{A}-\rho_{B}} \quad \text { and } \quad s_{B}=\frac{\bar{s}\left(1-\rho_{B}\right)}{2-\rho_{A}-\rho_{B}} .
$$

A natural question to ask at this point is how the software industry will be affected if the producer of the $A$ machine makes it more compatible with $B$ software. It can easily be verified from the above two equations that $d s_{A} / d \rho_{A}<0$, whereas $d s_{B} / d \rho_{A}>0$. That is, when machine $A$ becomes more compatible with $B$ software, some programmers will switch from writing $A$-software to writing $B$-software, because $B$ software applications can run on 
both machines. ${ }^{5}$

\section{Technological Advance and Standardization}

A radical technology change requires (or sometimes is defined by) a complete redesign of the product or service, its features, and even its function. When facing a technological revolution, the first question that comes to mind is whether the new technology will be adopted, given the large installed base of the existing technology. Consumers and producers face constant technology changes in every part of their lives. LP (long-play) records have been replaced by a digital CD (compact-disk) technology. CDs have been replaced by MP3 players. Video cassettes are replaced by DVDs (digital video disks).

David (1985), Besen (1992), and Besen and Farrell (1994) provide some fascinating examples of choices of compatibility such as finding alternatives to the QWERTY keyboard standard and AM versus FM stereo broadcasting. Some of these examples, such as the inferiority of the QWERTY keyboard and the superiority of SONY's Beta video format, have been disputed in Liebowitz and Margolis $(1990,1994,1995) .{ }^{6}$ A more recent example of how network effects might influence the incentives to adopt a new technology is the vehicle-tovehicle (V2V) communication network. V2V exchanges information about position, speed, direction, and time among connected automobiles. Adjacent cars can adjust their speed and distance to avoid collision and congestion. The Economist (Tech Report, p. 20, June 6, 2009) reports that V2V becomes socially beneficial when as a few as 3-5 percent of cars are equipped with this technology, because the responses of those who are equipped influence the overall flow of traffic, thus benefiting everyone. However, one may expect the adoption of $\mathrm{V} 2 \mathrm{~V}$ to be very slow because no consumer would buy a $\mathrm{V} 2 \mathrm{~V}$ device for the sake of benefiting those who do not buy it. This raises the question of whether there is a need for the regulator to intervene in this market. Section 8 briefly discusses the pros and cons of government

\footnotetext{
${ }^{5}$ This result may not hold if we allow the software industry to grow (an increase in $\bar{s}$ under the above formulation).

${ }^{6}$ SONY's Betamax was introduced in 1975 and conceded defeat to VHS in 1988.
} 
intervention in the form of subsidies and standard setting in network industries.

To analyze strategic technology adoption, consider a game played by two firms (or any two significant users), as displayed in Table 1. Both firms' profits exhibit network externalities if

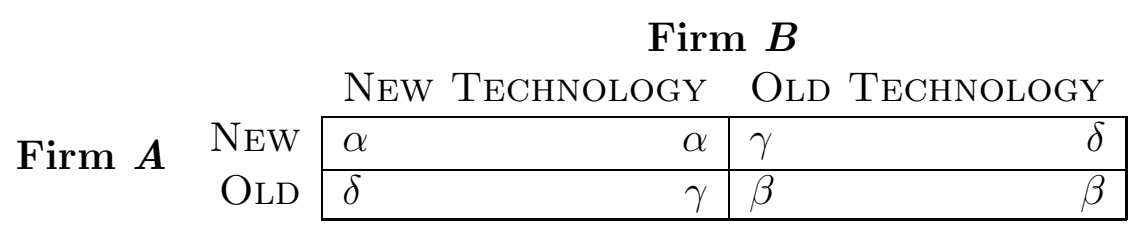

Table 1: New technology adoption game.

$\alpha>\delta$ and $\beta>\gamma$. That is, each firm earns a higher profit by adopting the same technology as the other firm regardless of which technology is chosen. There exist two Nash equilibria for the technology adoption game displayed in Table 1 given by (NEw, NEw) and (OLD, OLD).

The existence of multiple equilibria in this game raises the question of how the two firms coordinate their actions. Farrell and Saloner (1985) provide the following terminology for two possible separate market failures. If (OLD, OLD) is the Nash equilibrium outcome, and if the outcome (NEw, NEw) Pareto dominates the outcome (OLd, OLd) so that $\alpha>\beta$, then we call this situation excess inertia. If (NEw, NEw) is the Nash equilibrium outcome, and if the outcome (Old, OLd) Pareto dominates the outcome (NEw, NEw) so that $\alpha<\beta$, then we call this situation excess momentum. Clearly, under perfect information, if firms announce their choice of technology sequentially, then neither excess inertia nor excess momentum can be a subgame-perfect equilibrium. ${ }^{7}$

Katz and Shapiro (1992) provide the conditions under which there is a tendency to rush into new, incompatible technologies (excess momentum by newly entering firms). Farrell and Saloner (1986a) analyze a dynamic model consisting of old and new users who enter the market at different times. Unlike the static model, dynamic models can capture the externality inflicted on old users by the choices made by newly entering users. Katz and Shapiro

\footnotetext{
${ }^{7}$ Farrell and Saloner (1985) characterize some other equilibria under incomplete information and communication.
} 
(1986b) show that sponsored technologies are more likely to be adopted than unsponsored technologies. A technology is said to be sponsored if a single firm controls the property rights to the technology, or if there are significant barriers to entry. In contrast, a technology is unsponsored if there is free entry of firms who offer this technology. Choi (1994a, 1996b) and Choi and Thum (1998) investigate the tradeoff between early standardization and late standardization (standardization after the relative qualities of the competing standards become known) and demonstrate that users adopt early standardization more frequently than is socially optimal. For the monopoly case, Choi (1994b) demonstrates how firms can "force" consumers to make repeated purchases by introducing new, incompatible models. On the international level, Gandal and Shy (2001) analyze strategic standard recognition policies among countries and illustrate cases in which a welfare-maximizing government recognizes foreign standards even if the standards of the domestic country are not recognized by the foreign country.

If a newly improved technology is incompatible with an old technology, new consumers (or firms) may face a tradeoff between reaping the benefits associated with the improved technology and continuing to enjoy connectivity with "old" consumers who may not be able to switch. Shy (1996) considers a discrete-time, overlapping-generations (OLG) economy, where in each period the consumer population of the economy consists of two groups of individuals: $N_{Y}$ young consumers and $N_{O}$ old consumers. Figure 5 illustrates possible consumer preferences (or, firms' iso-profit curves) in the space of network size and the value of technologies.

$T_{1}$ and $T_{0}$ denote the quality of the new and old technology where $T_{1}>T_{0}$ indicates that the new technology is an improvement. The young generation consumers (firms) gain utility (profit) from the quality of a technology and the network size, which is the number of other consumers (firms) adopting the same technology. Figure 5 (left) illustrates "young" users (consumers or firms) who choose the newly improved technology, a choice that leaves them incompatible with "old" users. Figure 5 (right) illustrates the opposite case in which the gains from preserving compatibility dominate the benefits from adopting the newly improved 

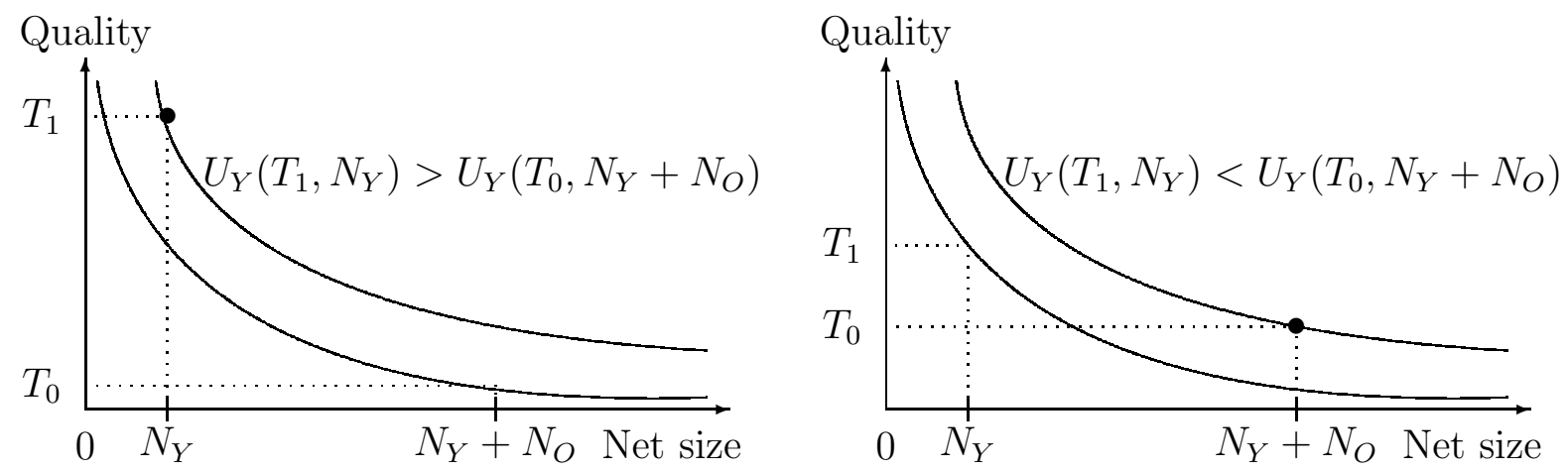

Figure 5: Tradeoff between quality of technology and network size. Left: Young choose the new, incompatible technology. Right: Young choose old compatible technology.

technology.

Finally, Schumpeter (1994) — a recent edition of Joseph Schumpeter's 1943 classic bookhas suggested that economic growth is not governed by continuous capital accumulation but occurs through a sequence of discrete technology revolutions. Using his words: "...they occur in discrete rushes which are separated from each other by spans of comparative quiet." Cabral (1990) and Chou and Shy (1993b) provide a network interpretation of Schumpeter's view of discrete technology changes. When software writers believe that a totally new set of technologies will be introduced in the future, all developers of new software stop development based on old standards and start developing software for a new standard before the new standard is actually marketed.

Figure 6 shows cycles of innovation from Schumpeter's perspective. Each cycle begins with the introduction of generation $g$ technology at $t=D^{g}$ ( $D$-day) and has duration $\Delta$. However, because at the introduction date, generation $g$ technology lacks sufficient software, consumers start buying generation $g$ only at the marketing date $t=M^{g}=D^{g}+G(M$ day). The period $G^{g}$ between the $D$-day and the $M$-day is called the gestation period of generation $g$ technology. During this period consumers buy only the old generation $g-1$ technology, while software is written only for the new generation $g$ technology. 
Duration of generation $g$ (only $g$ software is developed)

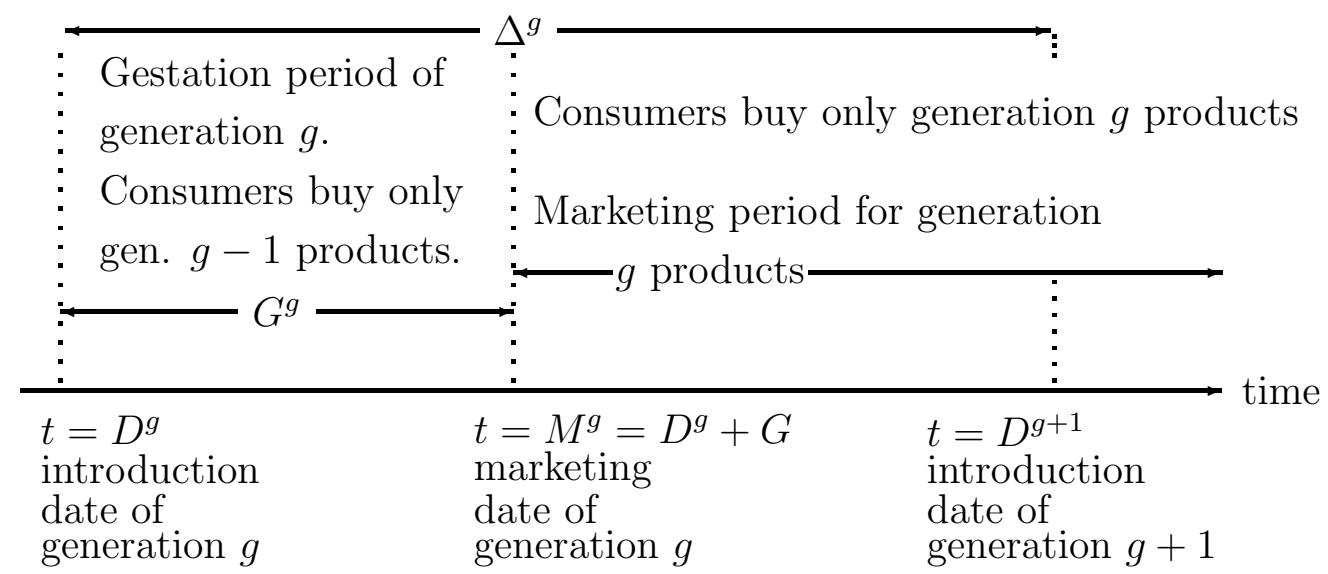

Figure 6: A network economics interpretation of Schumpeterian technology replacements.

\section{Two-sided Markets}

The theory of two-sided markets analyzes demand and supply spillovers between two markets for complementary services. The basic idea is rather intuitive. New stores and shopping malls emerge when more people settle in a certain area, and the availability of stores and shopping malls attracts new residents. When a certain hardware becomes more popular, software writers increase the variety of software written for this specific brand; and a machine that is supported by a larger variety of software is purchased by more consumers. Highly circulated newspapers attract more advertising, which either enhances or reduces circulation, depending on whether consumers gain or lose utility from reading ads. Dating bars with more female visitors attract more male visitors, and females are attracted to dating bars with more male visitors. This leads some dating bars to reduce or eliminate the admission fee charged to one of the sexes and increase the fee charged to the opposite sex in an attempt to equalize their numbers. A final example is taken from the payment card industry, which includes brand-name debit, credit, and prepaid cards. In this industry, if more merchants accept a certain payment card, more buyers adopt this card, which then induces more merchants to adopt this card, and so on...

The example of payment cards highlights the limitation of the two-sided market theory, 
because under full capacity no new spillovers between buyers and merchants can be created. More precisely, no additional network effects can be generated once most buyers already use payment cards and most merchants accept merchant cards. Therefore, policy conclusions of two-sided market models should be confined to immature markets.

Research on two-sided markets gained momentum in the late 1990s, when central banks and antitrust authorities began investigating how brand-name payment card companies coordinate their so-called interchange fees (the fee charged by the bank that issues the card to the bank that handles the merchant's request for payment). The card companies defended their fee coordination by claiming that, because of the cross-market externalities that characterize two-sided markets, the adoption of payment cards by buyers and merchants would not reach their efficient levels in the absence of interchange fees. Figures 7(a) and 7(b) illustrate a typical four-party payment card industry as described in Baxter (1983).

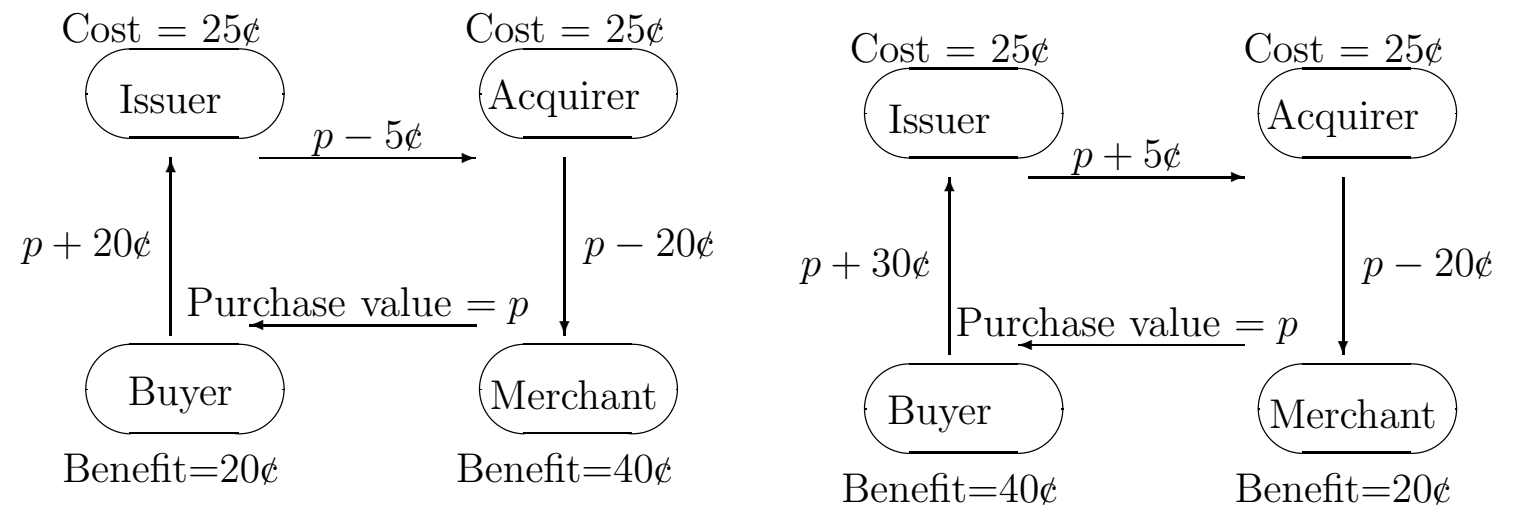
(a) Positive issuer fee (interchange fee)
(b) Negative issuer fee (interchange subsidy)

Figure 7: Two-sided market: Payment cards

The left sides of Figures 7(a) and 7(b) illustrate the card issuers' market (buyers' banks issue brand-name credit and debit cards to buyers). The right sides illustrate the acquirers' market (merchant banks receive merchants' requests for payments). The combined markets (left and right side) are termed two-sided because merchants benefit when more cards are issued to potential buyers, and buyers benefit when more merchants accept cards.

Figure $7(\mathrm{a})$ illustrates a buyer who purchases a product or a service from a merchant and 
pays a price $p$. This buyer is willing pay additional 20 cents for using a card instead of paying cash. Similarly, the merchant is willing to sacrifice up to 40 cents of her revenue in order to avoid handling cash. Suppose that the merchant's bank (the acquirer) is different from the buyer's bank (the bank that issues the payment card to the buyer). Also, suppose each bank incurs a cost of 25 cents for every card transaction. Clearly, in this ad hoc example, the transaction should be paid for with a card, because the total benefit from paying with a card (20 cents plus 40 cents) exceeds the total cost (25 cents plus 25 cents).

For some reason, most of the literature on payment cards has tended to emphasize the case of positive issuer fees as illustrated in Figure 7(a). In this case, in the absence of interchange fees, this transaction will not be paid for with a card because the issuing bank will not be able to recover the 25 cents cost from the buyer whose benefit is only 20 cents. This means that the issuer must be compensated by the merchant (who is not a customer of the issuing bank). This compensation is accomplished by levying an issuer fee (interchange fee) of 5 cents on the acquiring bank, which is consequently passed on to the merchant in the form of a higher merchant fee (and eventually to the buyer in form of a higher retail price).

Figure 7(b) illustrates an opposite scenario in which the issuer must subsidize (instead of tax) the merchant via the acquirer in order to induce the merchant to prefer accepting a payment card over cash. A negative interchange fee is needed to transfer the buyer's gain from a card transaction to the merchant, because the merchant's gains are insufficient to cover the acquirer's cost. Figure 7(b) demonstrates that this transaction can be accomplished by charging the buyer a 30 cents card use fee, out of which 5 cents are transferred to the acquirer. The acquirer then charges a 20 cents merchant fee for each card transaction and therefore breaks even.

So, what can we conclude from the above analysis? Should antitrust authorities allow card associations to coordinate positive issuer fees as demonstrated in Figure 7(a)? Recently, some authors began to realize that the data are insufficient to conclude which of the two cases illustrated in Figures 7(a) or 7(b) applies. For example, Evans and Schmalensee (2005) write, "...there is no basis in economics for concluding that the privately set interchange fee 
is just right." To conclude the theoretical discussion, it must be emphasized that the two cases illustrated in Figures 7(a) and 7(b) may no longer be relevant to mature markets since by now most buyers have payment cards and most merchants accept payment cards. In mature markets, interchange fees (above marginal costs) may not be needed.

On the empirical side, Rysman (2004) estimates the importance of network effects in the market for the Yellow Pages. The Yellow Pages directory can be viewed as a two-sided market because consumers' demand is enhanced with the number of advertised merchants, and merchants' demand for advertising is enhanced with the number of users. Thus, the two demand functions are interrelated. Note that this interdependence is with respect to the number of users in each market and not via the conventional cross-price-elasticity effects. The same paper also examines the welfare tradeoff between competition and monopoly under network effects and concludes that network effects are not strong enough to outweigh the benefits of entry. Kaiser and Wright (2006) obtain estimates of the parameters of a two-sided market with competing magazine publishers by asking what markup is charged to advertisers relative to that charged to readers. Their results hint that advertisers value readers more than readers value advertisements, and that as a result, magazines subsidize cover prices and make their profit from advertisers. Rysman (2007) establishes a regional correlation between consumer use and merchant acceptance within the four major credit card networks (Visa, MasterCard, American Express and Discover) ${ }^{8}$

The two-sided market literature makes it clear that it is important to distinguish the source of the externality. In matching markets (like the singles bar example discussed above) consumers on one side care about the number of consumers on the other side only because a higher number increases the probability of a good match, but they end up consuming only one instance on the other side. Hence, in some two-sided markets the externality is the expectation of a higher-quality match. To some degree, the literature on two-sided markets

\footnotetext{
${ }^{8}$ Although a complete list of contributions to two-sided markets is too long to be included in a short survey, the interested reader can consult Chakravorti and Shah (2003), Gans and King (2003), Rochet (2003), Wright (2003), Roson (2005), Armstrong (2006), Schwartz and Vincent (2006), Rochet and Tirole (2006), Bolt and Chakravorti (2008), Hayashi (2008), Rysman (2009), and Verdier (Forthcoming).
} 
resembles the literature on the components approach, surveyed in Section 3.2, in which compatibility enhances the variety of systems from which buyers can choose. In contrast, the network externalities approach of Section 3.1 emphasizes the direct gains from expanding the network of users, because buyers benefit from communicating with many other users; and the software approach discussed in Section 3.3 emphasizes the benefits derived from consuming a variety of supporting services.

As a final note, one may wonder how the analysis of two-sided markets differs from that of other markets in which network effects are present. Rysman (2009) suggests that the literature on two-sided markets is distinguished from the literature on network effects by its focus on the pricing decisions of an intermediary and is therefore a subset of the literature on network effects. In view of the supporting services (or indirect network externalities) approach discussed in Section 3.3, Church, King, and Krause (2008) suggest that the distinction is related to whether the hardware (software) firms internalize the effect on the demand for software (hardware) when making pricing decisions.

\section{Information Networks and Intellectual Property}

The dissemination and reproduction of information can be thought of as a network. Figure 8 displays some possible patterns in which information can be transmitted among $\eta$ agents.

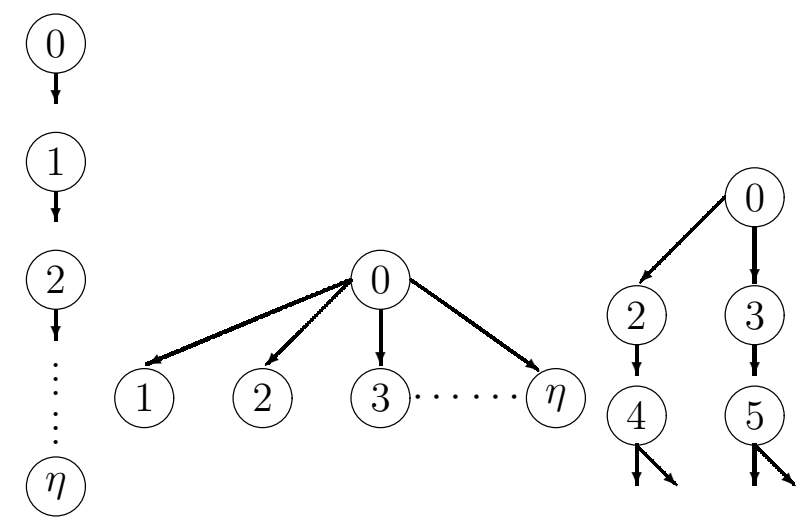

Figure 8: Left: "Vertical" information transmission. Middle: "Horizontal" information transmission. Right: "Mixed" transmission. Note: Agent 0 is the information provider. 
Figure 8 is difficult to interpret without being specific about the precise nature of the information and the technology used to spread the information. For example, gossip can travel vertically (down the road), or horizontally (one person is responsible for all gossip). The information path of the contents of a hardcover book borrowed from a library resembles vertical information transmission because no two people can read the same book at the same time. In contrast, the path of information from online newspapers resembles horizontal transmission of information because one web site can be read simultaneously by many viewers. Downloading Amazon Kindle books and iTune songs also resembles horizontal information transmission because all users download from a single server. Photocopying can take all three forms; however, the vertical form is of most interest because it degrades quality (a photocopy of a photocopy is generally of lower quality than the original).

The nature of the technology used to transmit information becomes even more important if we view Figure 8 as describing the reproduction of information. Different reproduction technologies may differ in the quality of the copies they generate, which may influence how information is priced. The books by Shapiro and Varian (1998), Kahin and Varian (2000), and Varian, Farrell, and Shapiro (2004) provide extensive discussions of information markets as well as pricing and copyright issues.

\subsection{Libraries and information sharing}

Because most libraries are public institutions we sometimes fail to realize the economic mechanism driving these institutions. In this discussion, the definition of a library extends to include nonpublic institutions such as video rental stores and online providers of journal articles. Thus, from an economic perspective, libraries can be viewed as places where information is rented as opposed to bookstores, where information is sold. Bakos, Brynjolfsson, and Lichtman (1999) demonstrate that sharing information does not necessarily lead to lower profits. Varian (2000) proposes a model that shows that publishers can enhance their profits by selling to libraries rather than directly to individuals. Both papers contain references to literature from the 1980s that was stimulated by concern that the availability of low-cost 
photocopying might generate losses for publishers.

Suppose there are $\eta$ potential information users (readers, in what follows) and $\lambda$ libraries. Assume that the number of libraries is smaller than the number of readers, $\lambda \leq \eta$. The utility of each reader is

$$
U= \begin{cases}\beta-p^{b} & \text { if she buys and owns the information } \\ \beta-p_{i}^{r}-\delta & \text { if she borrows (rents) from library } i \\ 0 & \text { does not read this information, }\end{cases}
$$

where $\beta$ is the utility derived from reading this information, $p^{b}$ is the price of buying this information, $p^{r}$ is the rental fee charged by the library, and $\delta$ measures the disutility from having to go to the library and wait on line or wait for the book to be recalled from another user.

Consider a monopoly publisher who owns the copyright to a certain book or journal with marginal cost $\mu$. This publisher's profit from selling directly to readers at the monopoly price $p=\beta$ is $\pi^{b}=\eta(\beta-\mu)$. Instead, this publisher can sell one copy to each of the $\lambda$ libraries for price $p_{i}=(\beta-\delta) \eta / \lambda$, where $\beta-\delta$ is the rental fee a library charges each borrower and $\eta / \lambda$ is the number of borrowers from each library $i, i=1, \ldots, \lambda$. Hence, the profit of the publisher from selling to libraries is $\pi^{r}=\left(p_{i}-\mu\right) \lambda=(\beta-\delta) \eta-\mu \lambda$. It follows that selling to libraries is more profitable for the publisher than selling directly to individuals if $\delta<(\eta-\lambda) \mu / \eta$, which happens if the disutility of going to library $\delta$ is low, the unit production cost $m$ is high, or the number of readers per library $\eta-\lambda$ is sufficiently high.

Finally, Hausman and Sidak (2009) examine the consumer-welfare implications of Google's project to scan a large proportion of the world's books into digital form. They argue that the increasing access of consumers to orphan books (books for which the copyright owners cannot be found) is tantamount to creating a new product that can yield large gains in consumer welfare. 


\subsection{Copying and piracy}

Digital convergence (the transformation of printed, analog audio, and analog video material to binary files), the increased dependence on computer software, and the increase in connectivity via the Internet have made copying easier than ever. The previous section asked whether the existence of libraries reduces or enhances publishers' profits. This section asks the same question about the influence of digital copying via the Internet and file-sharing networks.

The economics literature has identified several situations in which sellers of copyrighted material may benefit from some degree of infringement on their intellectual property rights. In theoretical papers, Conner and Rumelt (1991), Shy and Thisse (1999), and Peitz (2004) have demonstrated that the existence of strong network externalities implies that a firm's earnings need not be reduced as a result of piracy, as long as the demand for legal copies is enhanced by the distribution of illegal copies. ${ }^{9}$ Peitz and Waelbroeck (2006b) find that publishers can enhance their profits by allowing free downloading and sampling of digital products, because consumers are willing to pay more if the match between product characteristics and buyers' tastes is improved.

On the empirical side, Givon, Mahajan, and Muller (1995) estimate the degree to which an increase in illegal use of software boosts the demand for buying legal copies. Using data on spreadsheets and word processors in England, they show that although six of every seven software users used pirated copies, these pirates were responsible for attracting more than 80 percent of new software buyers, thereby significantly increasing the legal diffusion of software. More recently, Zentner (2006), Liebowitz (2006), Rob and Waldfogel (2006, 2007), De Vany and Walls (2007), Oberholzer-Gee and Strumpf (2007), and Waldfogel (2009) demonstrate empirically that piracy and free downloads do not necessarily lead to loss of sales of music or movie titles. These results refute claims made by some publishers that the number of pirated copies is a good measure of lost sales.

\footnotetext{
${ }^{9}$ Other theoretical contributions include Takeyama (1994, 1997), Slive and Bernhardt (1998), Gayer and Shy (2003b), and a critical review by Peitz and Waelbroeck (2006a).
} 
Figure 9 (bottom) illustrates a saturated market in which unpaid downloads crowd out legitimate sales. Figure 9 (top) illustrates the polar case where unpaid downloads enhance the demand for and sales of legitimate copies.

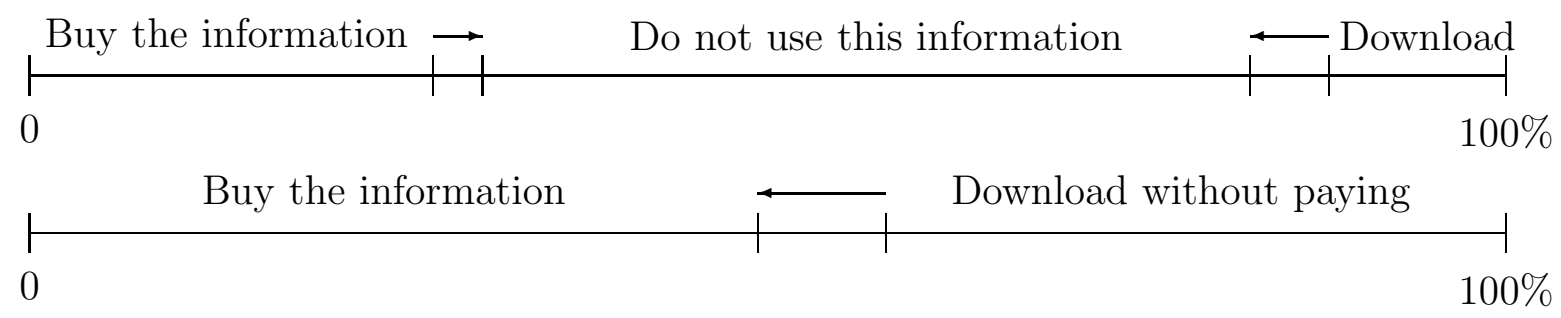

Figure 9: Top: Growing or partially served market. Bottom: Saturated market. Note: Intervals illustrate how the entire market is divided among the potential user population.

Commonly used anti-piracy measures include litigation and taxation of complementary hardware. Gayer and Shy (2003a) question the usefulness of hardware taxation by characterizing situations in which the resulting decline in hardware sales would also result in lower demand for software. Gayer and Shy (2006) argue that publishers and artists may have conflicting interests with respect to the enforcement of copyright protection.

\section{Social Influence: Conformity, Vanity, and Snobbism}

Although economists and sociologists frequently approach social problems from different perspectives, research in network economics has contributed to the building of bridges between these two disciplines, especially in the analysis of social behavior.

Social network effects are often manifested in our daily language in phrases like "keeping up with the Joneses," or "my neighbor's grass is always greener." Network economics offers a broader characterization of consumer behavior and new insights behind the organization of firms. For example, Shy (2007) shows how conformity and nonconformity can be used to explain and simulate changes in the proportions of secular and religious people. Hayes and Schaefer (2009) explain why CEO pay levels in the United States have risen 10 times faster than the average worker's wages since the 1970s. The conjecture is that because relative status matters, a firm's reputation is enhanced by paying its CEO an above average salary. 
They call this the "Lake Wobegon" effect where, according to Garrison Keillor, all children are "above average."

Young (1996) analyzes the creation of standards via conventions. When roads were not congested, people drove on the center of the road to avoid falling into the ditch on either side of the road. As congestion grew with population, coordination became necessary in order to avoid "transaction costs." Young presents an evolutionary model in which people base their driving decisions on a sample of past observations. Tipping (drivers switching from one side to another) may occur only if some people make their decisions randomly. Incidentally, traffic in Sweden used the right side of the road in 1718 and did so until 1734, when suddenly left-side driving was introduced. In 1967 Sweden switched back to the right side in order to facilitate crossing the borders to neighboring countries.

Perhaps the oldest convention in human behavior is that of gift giving. Genesis 32:20 tells the story of Jacob "...I will appease him with the present that goes before me. Then afterward I will see his face; perhaps he will accept me." Well, even if gifts can sometimes be interpreted as bribes (bribes also constitute a form of social networking), exchanges of gifts at birthday parties, weddings, and on Christmas are generated almost entirely by social pressure. The theory of revealed preference tells us that any gift other than cash is wasteful. Indeed, Waldfogel (1993) estimates that on average the receiver of a noncash gift is willing to pay no more that 83.9 percent of what the giver has actually paid ${ }^{10}$ Tremblay and Tremblay (1995) describe models that can predict that consumers may give cash and in-kind gifts based on altruistic, paternalistic, or warm-glow motives.

Leibenstein (1950) describes three external effects on consumer utility: (a) bandwagon effects and herd behavior, (b) nonconformity and snob effects, (c) Veblen's conspicuous consumption. The last effect may generate an upward-sloping demand function and will not be discussed here because the focus of this survey is network effects. ${ }^{11}$

The above-mentioned network effects are often observed in the form of herd behavior,

\footnotetext{
${ }^{10}$ See Solnick and Hemenway (1996) and Ruffle and Tykocinski (2000) for criticisms of these results.

${ }^{11}$ See Corneo and Jeanne (1997) and their references.
} 
which describes how individuals in a group may act together (often in a sequential manner) without planned direction. Banerjee (1992) and Bikhchandani, Hirshleifer, and Welch (1992, 1998) obtain herd behavior as an equilibrium when each decisionmaker has the option of following her own signal or following earlier decisionmakers. Choi (1997) investigates how the herd behavior of subsequent users influences the decisions made by early adopters in a model of sequential technology choice in which there are two new technologies with uncertain quality levels available for adoption. He shows that, in the presence of network externalities, once a technology is adopted and its quality is revealed, this technology may be chosen sequentially by everybody else even when it is common knowledge that the unproven technology has a much higher expected value. ${ }^{12}$

For some groups of products and services, consumers' utility actually diminishes when more consumers buy the same brand. That is, consumers prefer to be associated with a small group rather than with a large network. We refer to this behavior as negative network effects, nonconformity, vanity, or just snobbism. Grilo, Shy, and Thisse (2001) investigate how vanity behavior affects price competition in a model similar to the price equilibrium described in equation (3). Assuming $\alpha<0$ (negative network effects) reverses all the results obtained under positive network effects so that: (a) The firm with the larger installed base $\left(N_{A}>N_{B}\right)$ charges a lower price $\left(p_{A}^{I}<p_{B}^{I}\right)$ and earns a lower profit $\left(\pi_{A}^{I}<\pi_{B}^{I}\right)$. (b) The differences in equilibrium prices and profit levels increase with consumers' preference for a smaller network size (decrease in $\alpha$ ). (c) For similar installed bases, $N_{A} \approx N_{B}$, equilibrium prices and profits rise with a decrease in the network parameter $\alpha$. This shows that price competition is weakened when consumers place a higher value on smaller networks (more snobbism).

Finally, Church and King (1993) develop a model of network externalities to explain acquisition of languages. Let $\phi>0$ denote the cost of learning a new language. Suppose that there are $\eta_{E}$ native English speakers and $\eta_{H}$ native Hebrew speakers. Let $x_{H E}$ denote the number of native Hebrew speakers who learn English, and $x_{E H}$ the number of native

\footnotetext{
${ }^{12}$ For recent experiments on herding behavior, see Corazzini and Greiner (2007) and their references.
} 
English speakers who learn Hebrew. Define the utility of native English and Hebrew speakers by

$U_{E}=\left\{\begin{array}{ll}\alpha\left(\eta_{E}+n_{H E}\right) & \text { if she doesn't learn } H \\ \alpha \eta-\phi & \text { if she learns } H,\end{array} U_{H}= \begin{cases}\alpha\left(\eta_{H}+n_{E H}\right) & \text { if he doesn't learn } E \\ \alpha \eta-\phi & \text { if he learns } E,\end{cases}\right.$ where $\alpha>0$ measures the degree of importance of communicating with other people. This model predicts that either native English speakers learn Hebrew or vice versa, but not both. Extending the model to three languages generates an equilibrium in which each person will invest in learning one foreign language.

\section{Concluding Remarks}

This survey attempts to summarize part of the literature on network economics that has been published in the past 15 years. Although this survey provides references to some welfare results, it is clear that not much can be said about what role (if any) governments and regulating agencies should play in the selection of standards. The potential dangers from having governments mandate standards have been known since long before the development of this literature. A notable example is the FCC's choice of the CBS color TV standard in 1949. As Besen and Johnson (1986) explain, the market itself rejected the standard, leading the FCC to change its decision and to mandate the NBC standard, which was used from then until the introduction of digital high definition television (HDTV), which started in 1996.

The color TV example illustrates that markets can produce more socially desirable results than governments regarding the adoption of technological standards. To some degree, the mutual existence of multiple, incompatible standards may accelerate innovation because the sponsors of each standard will race to demonstrate superiority over competing technologies. Multiple standards are common in the payment industry. Buyers can pay with cash, debit cards, credit cards, prepaid cards, checks (not in all countries), and electronically via automated clearing houses $(\mathrm{ACH})$. The very fact that cash is legal tender does not preclude innovation in the direction of more convenient payment instruments. 
It would be useful to end this survey with some predictions on the directions of future research on network economics. Because future research will depend on the introduction of new network services, we must look at which industries are now experiencing rapid change. One of the fastest-changing areas is the rate of adoption of new payment instruments, where the issue of standardization plays a crucial role. For example, in some regions of East Africa, mobile phones now serve as a means to send and receive money for people who lack access to a bank account (estimated to be over 2 billion worldwide). Similar technologies (sometimes labeled person-to-person mobile banking) are now being introduced in other parts of the world, including the United States. Payment systems, such as the Single Euro Payments Area (SEPA) will be integrated with payment networks in other countries, a development that requires negotiations on standards setting. Finally, another line of research that is likely to emerge from the social influence models discussed in Section 7 deals with social networks and other virtual and nonvirtual organizations.

\section{References}

Armstrong, M. 2006. "Competition in two-sided markets." Rand Journal of Economics :668-691.

Baake, P. and A. Boom. 2001. "Vertical product differentiation, network externalities, and compatibility decisions." International Journal of Industrial Organization 19 (1-2):267284.

Bakos, Y., E. Brynjolfsson, and D. Lichtman. 1999. "Shared information goods." Journal of Law and Economics 42 (1):117-156.

Banerjee, A. 1992. "A simple model of herd behavior." Quarterly Journal of Economics 107:797-817.

Banerji, A. and B. Dutta. 2009. "Local network externalities and market segmentation." International Journal of Industrial Organization 27 (5):605-614. 
Baxter, W. 1983. "Bank interchange of transactional paper: Legal and economic perspectives." Journal of Law and Economics 26:541.

Becker, G. 1991. "A note on restaurant pricing and other examples of social influences on price." Journal of Political Economy 99:1109-1116.

Bensaid, B. and J. Lesne. 1996. "Dynamic monopoly pricing with network externalities." International Journal of Industrial Organization 14 (6):837-855.

Besen, S. 1992. "AM versus FM: The battle of the bands." Industrial and Corporate Change $1(2): 375-396$.

Besen, S. and J. Farrell. 1994. "Choosing how to compete: Strategies and tactics in standardization." Journal of Economic Perspectives 8:117-131.

Besen, S. and L. Johnson. 1986. "Compatibility standards, competition, and innovation in the broadcasting industry." Rand Corporation Report No. R-3453-NSF .

Bikhchandani, S., D. Hirshleifer, and I. Welch. 1992. "A theory of fads, fashion, custom, and cultural change as informational cascades." Journal of political economy 100 (5):992.

- 1998. "Learning from the behavior of others: Conformity, fads, and informational cascades." Journal of Economic Perspectives 12:151-170.

Bolt, W. and S. Chakravorti. 2008. "Economics of payment cards: A status report." Economic Perspectives 32 (4).

Brynjolfsson, E. and C. Kemerer. 1996. "Network externalities in microcomputer software: An econometric analysis of the spreadsheet market." Management Science 42:1627-1647.

Cabral, L. 1990. "On the adoption of innovations with 'network' externalities." Mathematical Social Sciences 19 (3):299-308.

Cabral, L., D. Salant, and G. Woroch. 1999. "Monopoly pricing with network externalities." International Journal of Industrial Organization 17 (2):199-214. 
Chakravorti, S. and A. Shah. 2003. "Underlying incentives in credit card networks." Antitrust Bulletin 48 (1):53-76.

Chen, J., U. Doraszelski, and J. Harrington. 2009. "Avoiding market dominance: Product compatibility in markets with network effects." Rand Journal of Economics 40 (3):455485.

Choi, J. 1994a. "Irreversible choice of uncertain technologies with network externalities." Rand Journal of Economics 25 (3):382-401.

—. 1994b. "Network externality, compatibility choice, and planned obsolescence." Journal of Industrial Economics 42:167-182.

- 1996a. "Do converters facilitate the transition to a new incompatible technology? A dynamic analysis of converters." International Journal of Industrial Organization $14(6): 825-835$.

_. 1996b. "Standardization and experimentation: ex ante vs. ex post standardization." European Journal of Political Economy 12 (2):273-290.

- 1997. "Herd Behavior, the "penguin effect," and the suppression of informational diffusion: An analysis of informational externalities and payoff Interdependency." Rand Journal of Economics 28 (3):407-425.

Choi, J. and M. Thum. 1998. "Market structure and the timing of technology adoption with network externalities." European Economic Review 42 (2):225-244.

Chou, C. and O. Shy. 1990. "Network effects without network externalities." International Journal of Industrial Organization 8 (2):259-270.

- 1993a. "Partial compatibility and supporting services." Economics letters $41(2): 193-197$. 
—. 1993b. "Technology revolutions and the gestation of new technologies." International Economic Review 34:631-645.

—. 1996. "Do consumers gain or lose when more people buy the same brand?" European Journal of Political Economy 12 (2):309-330.

Church, J. and N. Gandal. 1992. "Network effects, software provision, and standardization." Journal of Industrial Economics 40:85-103.

- 1993. "Complementary network externalities and network adoption." International Journal of Industrial Organization 11:239-260.

- 2005. "Platform Competition in Telecommunications." In Handbook of Telecommunications Economics, Volume 2, edited by M. Cave, S. Majumdar, and I. Vogelsang. Elsevier, 119-155.

Church, J. and I. King. 1993. "Bilingualism and network externalities." Canadian Journal of Economics 26:337-345.

Church, J., I. King, and D. Krause. 2008. "Indirect network effects and adoption externalities." Review of Network Economics 7:337-358.

Conner, K. and R. Rumelt. 1991. "Software piracy: An analysis of protection strategies." Management Science 37:125-139.

Corazzini, L. and B. Greiner. 2007. "Herding, social preferences and (non-) conformity." Economics Letters 97 (1):74-80.

Corneo, G. and O. Jeanne. 1997. "Conspicuous consumption, snobbism and conformism." Journal of Public Economics 66 (1):55-71.

Cremer, J., P. Rey, and J. Tirole. 2000. "Connectivity in the commercial Internet." Journal of Industrial Economics 48:433-472. 
David, P. 1985. "Clio and the Economics of QWERTY." American Economic Review 75:332-337.

de Palma, A., L. Leruth, and P. Regibeau. 1999. "Partial compatibility with network externalities and double purchase." Information Economics and Policy 11 (2):209-227.

De Vany, A. and W. Walls. 2007. "Estimating the effects of movie piracy on box-office revenue." Review of Industrial Organization 30 (4):291-301.

Dranove, D. and N. Gandal. 2003. "The Dvd-vs.-Divx standard war: Empirical evidence of network effects and preannouncement effects." Journal of Economics and Management Strategy 12 (3):363-386.

Economides, N. 1989. "Desirability of compatibility in the absence of network externalities." American Economic Review 79:1165-1181.

—. 1996a. "Network externalities, complementarities, and invitations to enter." European Journal of Political Economy 12 (2):211-233.

- 1996b. "The economics of networks." International journal of industrial organization $14(6): 673-699$.

Economides, N. and C. Himmelberg. 1995a. "Critical mass and network evolution in telecommunications." In Toward a Competitive Telecommunications Industry: Selected Papers from the 1994 Telecommunications Policy Research Conference, Gerard Brock (ed.). 4763.

. 1995b. "Critical mass and network size with application to the US fax market." NYU Stern School of Business Discussion Paper no. EC-95-11 .

Economides, N. and S. Salop. 1992. "Competition and integration among complements, and network market structure." Journal of Industrial Economics 40:105-123. 
Economides, N. and L. White. 1994. "Networks and compatibility: Implications for antitrust." European Economic Review 38 (3):651-662.

Einhorn, M. 1992. "Mix and match compatibility with vertical product dimensions." Rand Journal of Economics 23 (4):535-547.

Evans, D. and R. Schmalensee. 2005. "The economics of interchange fees and their regulation: An overview." MIT Sloan Working Paper No. 4548-05 .

Farrell, J. and P. Klemperer. 2007. "Coordination and lock-In: Competition with switching costs and network effects." In Handbook of Industrial Organization, Volume 3, edited by M. Armstrong and R. Porter. Elsevier, 1967-2072.

Farrell, J., H. Monroe, and G. Saloner. 1998. "The vertical organization of industry: Systems competition versus component competition." Journal of Economics and Management Strategy 7 (2):143-182.

Farrell, J. and G. Saloner. 1985. "Standardization, compatibility, and innovation." Rand Journal of Economics 16:70-83.

. 1986a. "Installed base and compatibility: Innovation, product preannouncements, and predation." American Economic Review 76:940-955.

—. 1986b. "Standardization and variety." Economics Letters 20 (1):71-74.

_. 1988. "Coordination through committees and markets." Rand Journal of Economics 19:235-252.

—. 1992. "Converters, compatibility, and the control of interfaces." Journal of Industrial Economics :9-35.

Gandal, N. 1994. "Hedonic price indexes for spreadsheets and an empirical test for network externalities." Rand Journal of Economics 25:160-170. 
- 1995. "Competing compatibility standards and network externalities in the PC software market." Review of Economics and Statistics 77:599-608.

Gandal, N., M. Kende, and R. Rob. 2000. "The dynamics of technological adoption in hardware/software systems: The case of compact disc players." Rand Journal of Economics $31: 43-61$.

Gandal, N. and O. Shy. 2001. "Standardization policy and international trade." Journal of International Economics 53 (2):363-383.

Gans, J. and S. King. 2003. "The neutrality of interchange fees in payment systems." Topics in Economic Analysis and Policy 3 (1):1069-1069.

Gayer, A. and O. Shy. 2003a. "Copyright protection and hardware taxation." Information Economics and Policy 15 (4):467-483.

- 2003b. "Internet and peer-to-peer distributions in markets for digital products." Economics Letters 81 (2):197-203.

- 2006. "Publishers, artists, and copyright enforcement." Information Economics and Policy 18 (4):374-384.

Givon, M., V. Mahajan, and E. Muller. 1995. "Software piracy: Estimation of lost sales and the impact on software diffusion." Journal of Marketing 59:29-37.

Gowrisankaran, G. and J. Stavins. 2004. "Network externalities and technology adoption: lessons from electronic payments." Rand Journal of Economics 35:260-276.

Goyal, S. 2007. Connections: an introduction to the economics of networks. Princeton University Press.

Grajek, M. 2010. "Estimating network effects and compatibility: Evidence from the Polish mobile market." Information Economics and Policy 22 (2):130-143. 
Greenstein, S. 1993. "Did installed base give an incumbent any (measurable) advantages in federal computer procurement?" Rand Journal of Economics 24 (1):19-39.

Grilo, I., O. Shy, and J. Thisse. 2001. "Price competition when consumer behavior is characterized by conformity or vanity." Journal of Public Economics 80 (3):385-408.

Hausman, J. and J. Sidak. 2009. "Google and the proper antitrust scrutiny of orphan books." Journal of Competition Law and Economics 5 (3):411-438.

Hayashi, F. 2008. "The economics of interchange fees and payment card fee structure: What is the optimal balance between merchant fee and payment card rewards?" Economic Research, Federal Reserve Bank of Kansas City Working Paper :08-06.

Hayes, R. and S. Schaefer. 2009. "CEO pay and the Lake Wobegon effect." Journal of Financial Economics 94:280-290.

Hotelling, H. 1929. "Stability in competition." Economic journal 39:41-57.

Jackson, M. 2008. Social and economic networks. Princeton University Press.

Jackson, M. and A. Wolinsky. 1996. "A strategic model of social and economic networks." Journal of economic theory 71 (1):44-74.

Kahin, B. and H. Varian. 2000. Internet publishing and beyond: the economics of digital information and intellectual property. MIT Press.

Kaiser, U. and J. Wright. 2006. "Price structure in two-sided markets: Evidence from the magazine industry." International Journal of Industrial Organization 24 (1):1-28.

Karni, E. and D. Levin. 1994. "Social attributes and strategic equilibrium: A restaurant pricing game." Journal of Political Economy 102:822-840.

Katz, M. and C. Shapiro. 1985. "Network externalities, competition, and compatibility." American economic review 75:424-440. 
- 1986a. "Product compatibility choice in a market with technological progress." Oxford Economic Papers 38 (supp):146-165.

—. 1986b. "Technology adoption in the presence of network externalities." Journal of Political Economy 94 (4):822.

- 1992. "Product introduction with network externalities." Journal of Industrial Economics 40:55-83.

—. 1994. "Systems competition and network effects." Journal of Economic Perspectives 8:93-115.

Leibenstein, H. 1950. "Veblen effects in the theory of consumers demand." Quarterly Journal of Economics 64 (2):183-207.

Liebowitz, S. 2006. "File Sharing: Creative destruction or just plain destruction?" Journal of Law and Economics 49 (1):1-28.

Liebowitz, S. and S. Margolis. 1990. "Fable of the keys." Journal of Law and Economics $33: 1-25$.

—. 1994. "Network externality: An uncommon tragedy." Journal of Economic Perspectives 8:133-150.

- 1995. "Are network externalities a new source of market failure." Research in Law and Economics 17 (0):1-22.

Markovich, S. 2008. "Snowball: a dynamic oligopoly model with indirect network effects." Journal of Economic Dynamics and Control 32 (3):909-938.

Markovich, S. and J. Moenius. 2009. "Winning while losing: Competition dynamics in the presence of indirect network effects." International Journal of Industrial Organization $27(3): 346-357$. 
Matutes, C. and P. Regibeau. 1988. "Mix and match": product compatibility without network externalities." Rand Journal of Economics :221-234.

Noam, E. 1992. "Network tipping and the tragedy of the common network." Communications \& Strategies :49-86.

Oberholzer-Gee, F. and K. Strumpf. 2007. "The effect of file sharing on record sales: An empirical analysis." Journal of Political Economy 115 (1):1-42.

Ohashi, H. 2003. "The role of network effects in the US VCR market, 1978-1986." Journal of Economics \& Management Strategy 12 (4):447-494.

Oren, S. and S. Smith. 1981. "Critical mass and tariff structure in electronic communications markets." Bell Journal of Economics :467-487.

Peitz, M. 2004. "A strategic approach to software protection: comment." Journal of Economics and Management Strategy 13:371-374.

Peitz, M. and P. Waelbroeck. 2006a. "Piracy of digital products: A critical review of the theoretical literature." Information Economics and Policy 18 (4):449-476.

- 2006b. "Why the music industry may gain from free downloading-The role of sampling." International Journal of Industrial Organization 24 (5):907-913.

Rob, R. and J. Waldfogel. 2006. "Piracy on the high C's: Music downloading, sales displacement, and social welfare in a sample of college students." Journal of Law and Economics $49(1): 29-62$.

—. 2007. "Piracy on the silver screen." Journal of Industrial Economics 55 (3):379-395.

Rochet, J. 2003. "The theory of interchange fees: A synthesis of recent contributions." Review of Network Economics 2 (2):97-124.

Rochet, J. and J. Tirole. 2006. "Two-sided markets: A progress report." Rand Journal of Economics 37:645-667. 
Rohlfs, J. 1974. "A theory of interdependent demand for a communications service." Bell Journal of Economics and Management Science 5:16-37.

Roson, R. 2005. "Two-sided markets: A tentative survey." Review of Network Economics $4(2): 142-160$.

Ruffle, B. and O. Tykocinski. 2000. "The deadweight loss of Christmas: comment." American Economic Review 90:319-324.

Rysman, M. 2004. "Competition between networks: A study of the market for yellow pages." Review of Economic Studies 71:483-512.

—. 2007. "An empirical analysis of payment card usage." Journal of Industrial Economics 55 (1):1-36.

- 2009. "The economics of two-sided markets." Journal of Economic Perspectives $23(3): 125-143$.

Schumpeter, J. 1994. Capitalism, socialism, and democracy. Routledge.

Schwartz, M. and D. Vincent. 2006. "The no surcharge rule and card user rebates: Vertical control by a payment network." Review of Network Economics 5 (1):72-102.

Shapiro, C. and H. Varian. 1998. Information rules. Harvard Business School Press.

Shy, O. 1996. "Technology revolutions in the presence of network externalities." International Journal of Industrial Organization 14 (6):785-800.

—. 2001. The economics of network industries. Cambridge University Press.

— 2007. "Dynamic models of religious conformity and conversion: Theory and calibrations." European Economic Review 51 (5):1127-1153.

Shy, O. and J. Thisse. 1999. "A strategic approach to software protection." Journal of Economics and Management Strategy 8 (2):163-190. 
Slive, J. and D. Bernhardt. 1998. "Pirated for profit." Canadian Journal of Economics 31:886-899.

Solnick, S. and D. Hemenway. 1996. "The deadweight loss of Christmas: comment." American Economic Review 86:1299-1305.

Takeyama, L. 1994. "The welfare implications of unauthorized reproduction of intellectual property in the presence of demand network externalities." Journal of Industrial Economics 42:155-166.

_ 1997. "The intertemporal consequences of unauthorized reproduction of intellectual property." Journal of Law and Economics 40 (2):511-522.

Taylor, L.D. 1994. Telecommunications demand in theory and practice. Kluwer Academic Pub.

Tremblay, C. and V. Tremblay. 1995. "Children and the economics of Christmas gift-giving." Applied Economics Letters 2 (9):295-297.

Varian, H. 2000. "Buying, sharing and renting information goods." Journal of Industrial Economics :473-488.

Varian, H., J. Farrell, and C. Shapiro. 2004. The economics of information technology: An introduction. Cambridge University Press.

Vega-Redondo, F. 2007. Complex social networks. Cambridge University Press.

Verdier, M. Forthcoming. "Interchange fees in payment card systems: A survey of the literature." Journal of Economic Surveys .

Waldfogel, J. 1993. "The deadweight loss of Christmas." American economic review 83:13281336.

- 2009. "Lost on the web: Does web distribution stimulate or depress television viewing?" Information Economics and Policy 21 (2):158-168. 
Wright, J. 2003. "Optimal card payment systems." European Economic Review 47 (4):587612.

Young, P. 1996. "The economics of convention." Journal of Economic Perspectives 10:105122.

Zentner, A. 2006. "Measuring the effect of music downloads on music purchases." Journal of Law and Economics 49 (1):63-90. 